\title{
Acute 1L-1 $\beta$ Luciferase Signal and Immune Response to Surface Modified Polyurethane-Type Shape Memory Polymers: A Pilot Study
}

\author{
Xinying Cheng ${ }^{1,4}$, Jian Fei ${ }^{2,3}$, Lin Ye $\mathrm{Ye}^{4}$, Marcela MM Bilek ${ }^{5}$ and Shisan Bao*1,6 \\ ${ }^{1}$ Discipline of Pathology and School of Medical Sciences, Bosch Institute, Australia \\ ${ }^{2}$ School of Life Science and Technology, China \\ ${ }^{3}$ Research Centre for Model Organisms, China \\ ${ }^{4}$ Centre for Advanced Materials Technology, Australia \\ ${ }^{5}$ Applied and Plasma Physics, Australia \\ ${ }^{6}$ Tongren Hospital, China \\ *Corresponding author: Shisan Bao, Discipline of Pathology and School of Medical Sciences, Bosch Institute, Australia
}

\section{ARTICLE INFO}

Received: 蔧 February 01, 2019

Published: 崲 February 14, 2019

Citation: Xinying Cheng, Jian Fei, Lin Ye, Marcela MM Bilek, Shisan Bao. Acute $1 \mathrm{~L}-1 \beta$ Luciferase Signal and Immune Response to Surface Modified Polyurethane-Type Shape Memory Polymers: A Pilot Study. Biomed J Sci \& Tech Res 14(4)-2019. BJSTR. MS.ID.002579.

\section{ABSTRACT}

Polyurethane-type Shape Memory Polymers (SMPU) are promising biomaterials due to the ability to change shape by external stimulus. However, SMPU suffer from hydrophobicity and bio-inertness which restricts their possibilities as implantable biomedical applications. Plasma Immersion Ion Implantation (PIII) is a one-step covalent method to functionalise SMPU and to create a tuneable, biocompatible surface by attaching biomolecules. In this pilot study, collagen was used to immobilise on PIII treated SMPU surfaces and SMPU \pm PIII and \pm collagen were subcutaneously implanted in $1 \mathrm{~L}-1 \beta$ mice. Real-time $1 \mathrm{~L}-1 \beta$ luciferase signal was detected at day 1 and acute inflammatory responses at day 7 were determined using H\&E staining histologically. The results indicate significantly less host immune responses to PIII treated SMPU with collagen coating. This pilot study provides a solid foundation for further acute/chronic study in vivo.

Keywords: SMPU; PIII; Collagen; Host Immune Response; Inflammation; Subcutaneous Implantation

\section{Introduction}

As one of smart materials, Shape Memory Polymers (SMP) have been investigated extensively for biomedical applications because of their shape memory properties [1], such as vascular stents, aneurysm occlusion devices, and clot extraction devices [2-5]. Polyurethane-type Shape Memory Polymers (SMPU), one of the most common SMP, have the advantage of a glass transition temperature closed to body temperature [6], facilitating the activation of shape memory recovery within the body. However, SMPU still suffer from inherent hydrophobicity and bio-inertness [7]. This may bring about immune reactions and poor tissue integration. Therefore, creating bioactive interfaces prior to implantation is of great importance [8].
Plasma surface treatments, such as Plasma Immersion Ion Implantation (PIII), are efficient methods to change surface properties without changing bulk properties, involving wettability, chemical structure, and hardness. These changes can contribute to the improvement of interactions between biomolecules and biomaterial surfaces [9]. Additionally, PIII enables one-step covalent attachment of biomolecules without the participance of any chemical reagents [10], facilitating the applications of SMPU in biomedical industry easily. It has been documented that protein can be covalently immobilised on PIII treated polymer surfaces, leading to the improvement of cell adhesion, proliferation, and viability on the interfaces [11-13]. In our previous study, covalent 
immobilisation of collagen has been observed on PIII treated SMPU surfaces in vitro [14]. Therefore, we aim to conduct a pilot study to study biocompatibility of SMPU \pm PIII and \pm collagen in vivo. The acute $1 \mathrm{~L}-1 \beta$ luciferase signal was detected in real time and acute inflammatory response to the implanted SMPU was determined at the histopathological level.

\section{Materials and Methods}

Polyurethane-type Shape Memory Polymers (SMPU) were purchased from DiAPLEX Co., Ltd (Tokyo, Japan). SMPU incorporates hard segments of 4, 4' Diphenylmethane Diisocyanate (MDI) and polyether type soft segments of polypropylene glycol and polyethylene glycol, as described [15].

Plasma Immersion Ion Implantation (PIII) was carried out at a pressure of $2 \times 10^{-3}$ Torr with an RF nitrogen plasma powered at $100 \mathrm{~W}$ and accelerated by high voltage pulsed bias of $20 \mathrm{kV}$ for pulse durations of $20 \mu \mathrm{s}$ at a frequency of $50 \mathrm{~Hz}$, as described previously [16]. The SMPU was treated for durations of $200 \mathrm{~s}$ and $800 \mathrm{~s}$, corresponding to ion implantation fluences of $2.5 \times 1015$ ions $/ \mathrm{cm}^{2}$ and $1 \times 101^{6}$ ions $/ \mathrm{cm}^{2}$ respectively [14]. PIII treatment was performed on SMPU samples 10 days prior to implantation and stored at room temperature. Collagen type I from rat tail was purchased from Sigma-Aldrich (cat. No. C3867, Sydney, Australia) and diluted to $10 \mu \mathrm{g} / \mathrm{ml}$ with PBS. Six types of SMPU samples $(1.5 \mathrm{~cm} \times 2 \mathrm{~cm})$ were prepared:
a) untreated SMPU,
b) $200 \mathrm{~s}$ PIII treated SMPU,
c) $800 \mathrm{~s}$ PIII treated SMPU,
d) collagen coated untreated SMPU,
e) $200 \mathrm{~s}$ PIII treated SMPU with collagen coating, and
f) $800 \mathrm{~s}$ PIII treated SMPU with collagen coating.

SMPU samples (diameter $=4 \mathrm{~mm}$, thickness $=0.5 \mathrm{~mm}$ ) were $\mathrm{im}$ planted in six subcutaneous pockets at the back of IL-1 $\beta$ luciferase mice (the Research Centre for Model Organisms, Shanghai, China), and all samples were sterilised using UV light in a biosafety cabinet for 15 min prior to implantation. Real time $1 \mathrm{~L}-1 \beta$ luciferase signal was detected using MAG Biosystems Lumazone imaging system. The harvested implants included surrounding tissues and capsules $(1.5 \mathrm{~cm} \times 1.5 \mathrm{~cm})$ were collected at day 7 for histological analysis. Total cell number in the capsule surrounding SMPU implants was determined using H\&E staining and analysed using one-way ANOVA in in GraphPad Prism Version 7.0 (GraphPad Software, CA, USA). This experiment has been approved by the University of Sydney Animal Ethics Committee (protocol number K20/12-2011/3/5634) and conducted in accordance with the Australian Code of Practice for the Care and Use of Animals for Scientific Purpose.

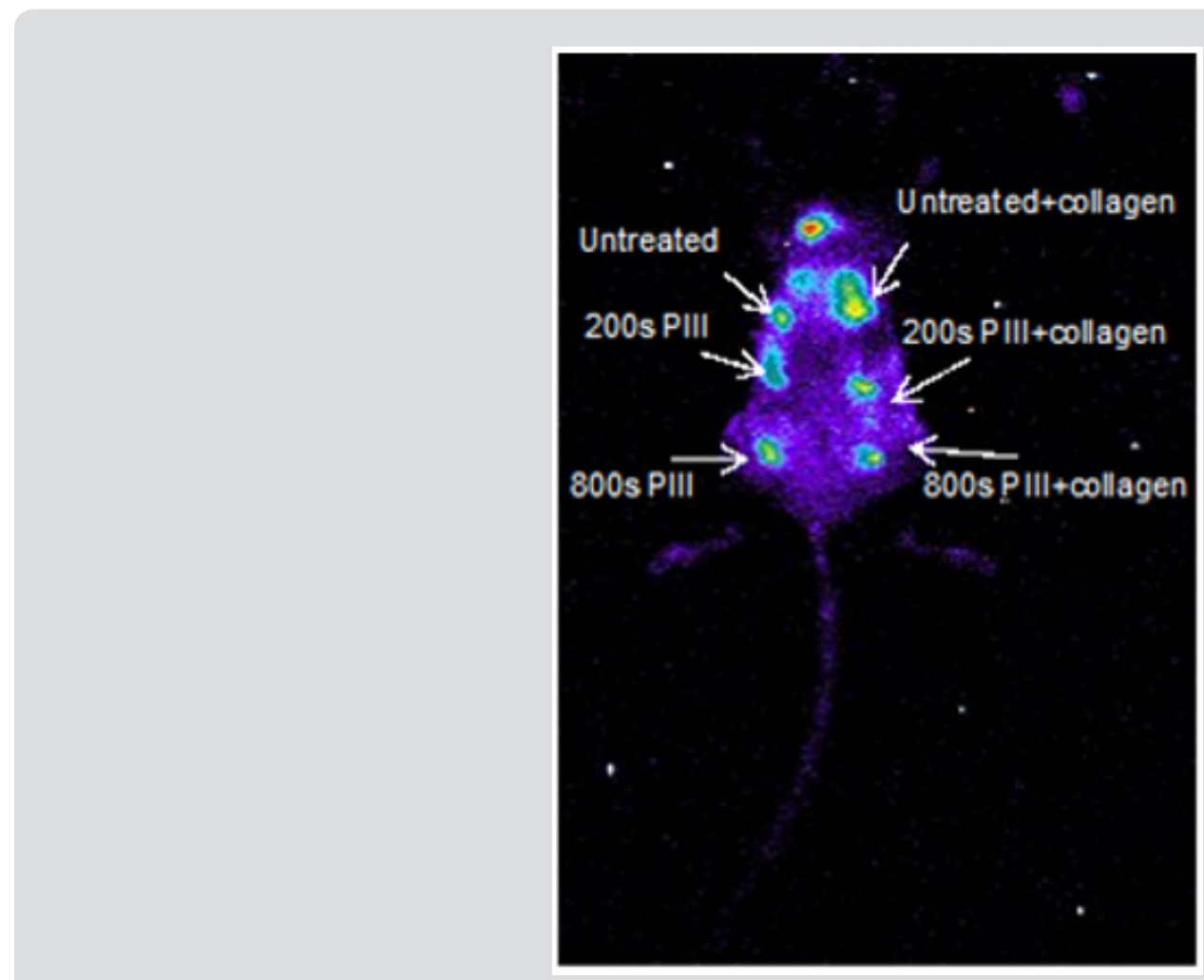

Figure 1: $1 \mathrm{~L}-1 \beta$ luciferase signal detected in SMPU at day 1 post implantation: untreated SMPU, 200s PIII treated SMPU, $800 \mathrm{~s}$ PIII treated SMPU, untreated SMPU with collagen coating, $200 \mathrm{~s}$ PIII treated SMPU with collagen coating, and $800 \mathrm{~s}$ PIII treated SMPU with collagen coating. 


\section{Results and Discussion}

Figure 1 shows the real-time $1 \mathrm{~L}-1 \beta$ expression of SMPU implants in the back of mice at day 1. Compared to other samples, untreated SMPU with collagen coating had a substantially higher level of acute immune response. Smaller $1 \mathrm{~L}-1 \beta$ areas were observed in both SMPU with 200 s/ 800s PIII treatment and collagen coating than those with PIII treatment only, indicating less acute immune response to PIII treated SMPU with collagen coated. Figure 2 shows total cell numbers in capsules surrounding SMPU implants using H\&E staining at day 7. Both 200 s PIII treated SMPU and $800 \mathrm{~s}$ PIII treated SMPU had significantly lower total cell numbers than untreated SMPU by $25.1 \%(\mathrm{p}<0.01)$ and $24.3 \%(\mathrm{p}<0.01)$, respectively. These two PIII treated SMPU also had lower total cell numbers than untreated SMPU with collagen coating by $25.4 \%$ (p $<0.01)$ and $24.6 \%(p<0.01)$, respectively. There was no significant difference between SMPU with 200 s PIII treatment and 400 s PIII treatment, while collagen coated SMPU with PIII treated for $200 \mathrm{~s}$ had a higher total cell number than collagen coated SMPU with 800 s PIII treatment $(\mathrm{p}<0.001)$. This can be attributed to that more collagen were immobilised on the $800 \mathrm{~s}$ PIII treated SMPU than on the $200 \mathrm{~s}$ PIII treated SMPU. In addition, no significant difference was observed between untreated SMPU and collagen coated untreated SMPU, which might be due to collagen replaced by other proteins in extracellular matrix.

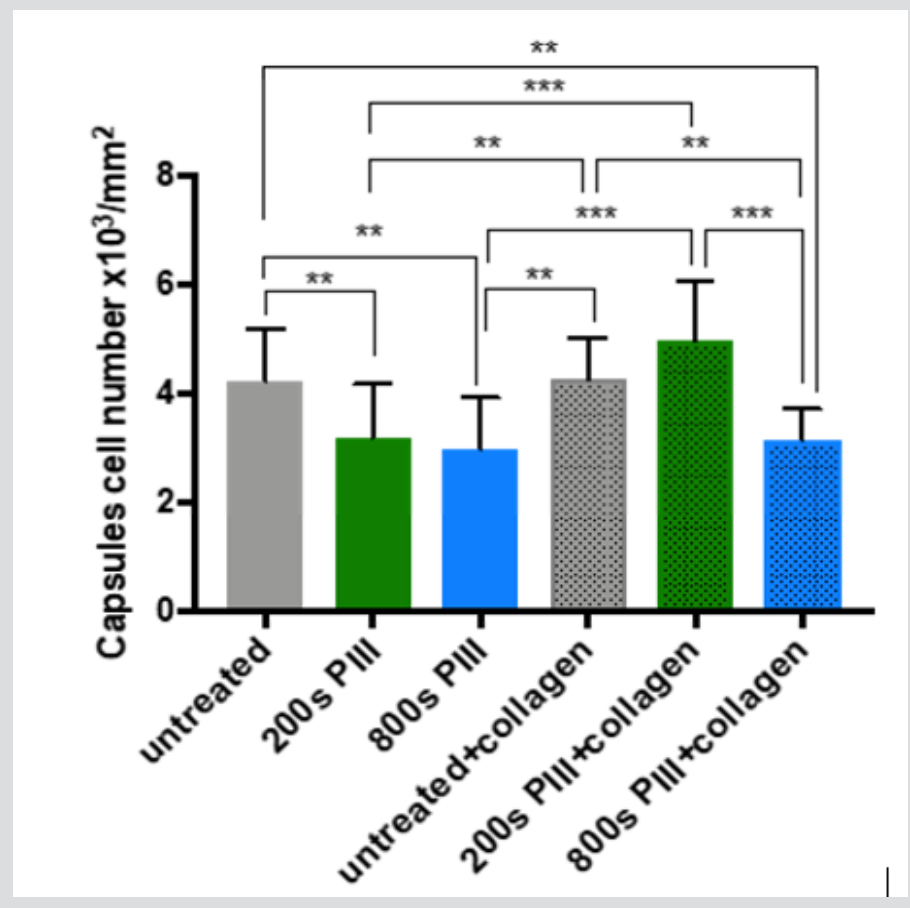

Figure 2: Total cell numbers quantified in capsules surrounding SMPU implants at day 7 post implantation, ${ }^{*} \mathrm{p}<0.05,{ }^{* *} \mathrm{p}<$ $0.01,{ }^{* * *} \mathrm{p}<0.001$.

\section{Conclusion}

By comparing SMPU \pm PIII and \pm collagen implants in vivo, significantly lower acute inflammatory responses were observed in PIII treated SMPU with collagen coating than other untreated or single treated (either PIII treatment or collagen coating) at day 7. This pilot study provides a solid foundation for further acute/ chronic inflammation study of SMPU as implantable biomedical applications.

\section{References}

1. Serrano MC, Ameer GA (2012) Recent insights into the biomedical applications of shape-memory polymers. Macromol Biosci 12: 11561171.

2. Wache HM, Tartakowska DJ, Hentrich A, Wagner MH (2003) Development of a polymer stent with shape memory effect as a drug delivery system. J Mater Sci Mater Med 14: 109-112.
3. Small Iv W, Wilson T, Benett W, Loge J, Maitland D (2005) Laser-activated shape memory polymer intravascular thrombectomy device. Opt Express 13: 8204-8213.

4. Géraldine M Baer, Ward Small, Thomas S Wilson, William J Benett, Dennis L Matthew (2007) Fabrication and in vitro deployment of a laseractivated shape memory polymer vascular stent. BioMed Eng Online 6: 43-50

5. Annick Metcalfe, Anne-Cécile Desfaits, Igor Salazkin, L’Hocine Yahia, Witold M Sokolowski (2003) Cold hibernated elastic memory foams for endovascular interventions. Biomaterials 24: 491-497.

6. Xue L, Dai S, Li Z, (2009) Synthesis and characterization of three-arm poly ( $\varepsilon$-caprolactone)-based poly (ester-urethanes) with shape-memory effect at body temperature. Macromolecules 42: 964-972.

7. Cherng JY, Hou TY, Shih MF, Talsma H, Hennink WE (2013) Polyurethanebased drug delivery systems. Int J Pharm 450: 145-162.

8. Bazaka K, Jacob MV (2012) Implantable devices: Issues and challenges. Electronics 2: 1-34. 
9. Weibel DE, Vilani C, Habert AC, Achete CA (2007) Surface modification of polyurethane membranes using acrylic acid vapour plasma and its effects on the pervaporation processes. J Membr Sci 293: 124-132.

10. Wakelin EA, Yeo GC, McKenzie DR, Bilek MM, Weiss AS (2018) Plasma ion implantation enabled bio-functionalization of PEEK improves osteoblastic activity. APL Bioengineering 2: 026109.

11. Zhang W, Chu PK (2008) Enhancement of antibacterial properties and biocompatibility of polyethylene by silver and copper plasma immersion ion implantation. Surf Coat Technol 203: 909-912.

12. Bax DV, Wang Y, Li Z, Maitz PK, McKenzie DR, et al. Binding of the cell adhesive protein tropoelastin to PTFE through plasma immersion ion implantation treatment. Biomaterials 32: 5100-5111.

13. Bax DV, Kondyurin A, Waterhouse A, McKenzie DR, Weiss AS (2014) Surface plasma modification and tropoelastin coating of a polyurethane

ISSN: 2574-1241

DOI: 10.26717.BJSTR.2019.14.002579

Shisan Bao. Biomed J Sci \& Tech Res

This work is licensed under Creative Commons Attribution 4.0 License

Submission Link: https://biomedres.us/submit-manuscript.php co-polymer for enhanced cell attachment and reduced thrombogenicity Biomaterials. 35: 6797-6809.

14. Cheng X, Kondyurin A, Bao S, Bilek MM, Ye LK (2017) Plasma immersion ion implantation of polyurethane shape memory polymer: Surface properties and protein immobilization. Appl Surf Sci 416: 686-695.

15. Mizue Kuriyagawa, Takanobu Kawamura, Shunichi Hayashi, Koh-Hei Nitta (2010) Reinforcement of polyurethane-based shape memory polymer by hindered phenol compounds and silica particles. J Appl Polym Sci 117: 1695-1702.

16. Kosobrodova E, Kondyurin A, McKenzie DR, Bilek MM (2013) Kinetics of post-treatment structural transformations of nitrogen plasma ion immersion implanted polystyrene. Nucl Instrum Methods Phys Res Sec 304: 57-66.

$\begin{array}{ll}\text { BIOMEDICAL } & \text { Assets of Publishing with us } \\ \text { RESEARCHES } & \text { - Global archiving of articles } \\ \text { - Immediate, unrestricted online access } & \text { - Rigorous Peer Review Process } \\ & \text { - Authors Retain Copyrights }\end{array}$

